\title{
A comparison of CDIO-based medical education and traditional medical educa- tion at Yangzhou University
}

\author{
Jinsong Wang ${ }^{1}$ Hongcan Shi ${ }^{1}$ Weijuan Gong ${ }^{1}$ Ying Zheng $^{1}$ Zhengbin Wang $^{1}$ \\ Honghai $\mathrm{Wu}^{1}$ \\ ${ }^{1}$ Medical School of Yangzhou University
}

\begin{abstract}
Ability of sustainable learning and skills of medical students are important. We assessed the effectiveness of CDIO based medical education in Yangzhou University. Sixty medical students at Yangzhou University volunteered to be part of a feasibility study for demonstrating the concept of CDIO. All medical students of CDIO-based group found the CDIO program to be very satisfactory, and all expressed that they would like to have further CDIO-based experiences if given the opportunity. The students of CDIO-based program and traditional program have different average mark of 86 and 77 for the OSCE $(\mathrm{p}<0.05)$ at the last test. CDIO could be useful in medical education.
\end{abstract}

Keywords: Medical education; CDIO; Objective structured clinical examination

\section{Background}

Continuous development and use of new evidences and technologies are characteristics in health care. Medical colleges, schools of medicine, and other health care educational programs have some new learning methods as problem-based learning (PBL), Case-Based learning (CBL). However, these methods of learning may not adequately evaluate mastery of essential clinical skills and measure cognitive learning in clinical settings [1].
Furthermore, clinical faculty members often see a disparity between performance of high achievers in the classroom and in clinical settings $[2,3]$. This inconsistency may stem from differences in testing for memorization of information and clinical application of knowledge. Therefore, the use of performance-based assessment methods, such as the CDIO in health care education is of fundamental importance [4]. CDIO engineering education model is the latest achievements of an international engineering education reform in recent years, founded in the Massachusetts Institute of Technology, where four letters of CDIO represent Conceive, Design, Implement and Operate. CDIO reform vision is for students to provide a systems and products with conceive-design-implement-operate under the context of emphasizing project-based engineering education so that students can master the deep technical base of knowledge, lead new products and new systems development and operation, and understanding of engineering technology research and development for social importance and strategic impact. Although medical education is different with engineering education, CDIO could give students more lifelike training before they be thrown into health care of society. At Yangzhou University, we investigated students feeling and used OSCE to assess the new way of learning based on CDIO concept. 


\section{Methods}

Sixty (60) medical students in their first year of clinical education at Yangzhou University volunteered to be part of a feasibility study for demonstrating the concept of CDIO.

\subsection{Ethics approval}

The Department Chair of the Clinical Research Ethics Committee at Yangzhou University approved the study and confirmed that the study conformed to all applicable guidelines and that ethical matters were dealt with accordingly. An information sheet and a consent form were given to all participating students in the study. All students participating in the study had been given an information session explaining the project and signed the form of consent prior to this study.

\subsection{Participants and tests}

Sixty (60) medical students were randomized divided into two groups of thirty students each in anesthesiology course. They were assessed using an objective structured clinical examination (OSCE). All participants completed three survey regarding the usefulness and efficiency of the CDIO-based program at last. The scores were 5 to 1 , according to strongly agree, agree, somewhat agree, disagree, and strongly disagree. All participants test by OSCE at three time-points (Start point, Mid-point and Last point) in the semester.

\subsection{Statistics analysis}

Examination marks are presented as mean \pm standard error. Generalized linear mixed models were used to compare the difference between two groups over three time-points. Data of evaluation ratings of students were analyzed by rank sum test. All analyses were performed using SAS version 9.2 software (SAS Institute, Cary, North Carolina, USA).

\section{Results}

Marks of OSCE were similar at the start point. However, different of averages over three time-points between two groups and the averages show in Table 1 $(\mathrm{p}<0.01)$. The marks were improved more quick in CDIO group than another group in mid-points and the difference between two groups was significant at last timepoints.

On a scale from 5 to 1 , both two groups' students rated the value of learning methods. Thirty medical students in CDIO-based program think program was helpful while all expressed that they will attend again if given the opportunity. The data showed in Table 2. The satisfaction level of participants was an average of 4.6 on a scale of 5 in CDIO-based program group.

Table 1 The differences of OSCE averages $\left(\bar{X} \pm S_{\bar{X}}\right)$ over three time-points between groups of CDIO based program and traditional program at Yangzhou University*

\begin{tabular}{lcccccc}
\hline \multirow{2}{*}{$\begin{array}{l}\text { Time- } \\
\text { points }\end{array}$} & \multicolumn{3}{c}{ CDIO-based program group } & \multicolumn{3}{c}{ Traditional program group } \\
\cline { 2 - 6 } & Start point & Mid-point & Last point & Start point & Mid-point & Last point \\
\hline Marks & $11 \pm 8$ & $60 \pm 9$ & $86 \pm 3$ & $\begin{array}{c}11 \pm 9 \\
\text { P }<0.01\end{array}$ & $40 \pm 13$ & $77 \pm 4$ \\
& & & & & \\
\hline
\end{tabular}

*Generalized linear mixed models were used to compare the differences of OSCE over three time-points by SAS PROC MIXED. 
Table 2 The participants' rating of CDIO-based program and traditional program at Yangzhou University $(n)$

\begin{tabular}{|c|c|c|c|c|c|c|c|c|c|c|}
\hline \multirow{2}{*}{$\begin{array}{l}\text { Numbers } \\
\text { of rating } \\
\text { scale }\end{array}$} & \multicolumn{5}{|c|}{ CDIO-based program group } & \multicolumn{5}{|c|}{ Traditional program group } \\
\hline & $\begin{array}{c}\text { Clinically } \\
\text { relevant }\end{array}$ & $\begin{array}{c}\text { Improving } \\
\text { clinical skills }\end{array}$ & Helpful & Difficult & $\begin{array}{l}\text { Will } \\
\text { again }\end{array}$ & $\begin{array}{c}\text { Clinically } \\
\text { relevant }\end{array}$ & $\begin{array}{c}\text { Improving } \\
\text { clinical skills }\end{array}$ & Helpful & Difficult & $\begin{array}{r}\text { Will } \\
\text { again }\end{array}$ \\
\hline $\begin{array}{l}\text { Strongly } \\
\text { agree }\end{array}$ & 20 & 22 & 17 & 10 & 30 & 14 & 15 & 13 & 6 & 18 \\
\hline Agree & 8 & 7 & 12 & 12 & 0 & 13 & 12 & 12 & 10 & 7 \\
\hline $\begin{array}{l}\text { Somewhat } \\
\text { agree }\end{array}$ & 2 & 1 & 1 & 8 & 0 & 1 & 1 & 2 & 12 & 2 \\
\hline Disagree & 0 & 0 & 0 & 0 & 0 & 1 & 1 & 1 & 1 & 2 \\
\hline $\begin{array}{l}\text { Strongly } \\
\text { disagree }\end{array}$ & 0 & 0 & 0 & 0 & 0 & 1 & 1 & 2 & 1 & 1 \\
\hline $\begin{array}{l}\text { Average } \\
\text { score }(1-5)\end{array}$ & 4.6 & 4.7 & 4.5 & 4.1 & 5 & 4.3 & 4.3 & 4.1 & 3.6 & 4.3 \\
\hline
\end{tabular}

Controls think the PBL and CBL were good, but it is independent with clinical setting. The satisfaction level of participants was an average of 4.1 .

\section{Discussion}

From the students' opinions, we concluded that the CDIO methodology provides a less stressful and a more helpful development learning experience than PBL and CBL. The students indicated that they would like to participate again. The experience is quite comparable to that of a clinic setting. Study showed that the students think PBL and CBL-learning could not give chance to take charge the situation and their patient [5] and experience indicate that the key ingredient is increased participation. Problem-based learning works best when students are engaged in a dynamic way while working through a case. In order for this interaction to occur, all students must be prepared to discuss the learning objectives for the case [6]. However, CDIO-based program gave them more chance to do as a doctor.

Although OSCE was an assessment for PBL-learning [7], it should show the effect of medical education. Our study shows the mark of CDIO-based group was higher than traditional group. CDIObased program allows the faculty to pinpoint student deficiencies from the integrated clinical workplaces. Since we record every activity of students, we can trace students' thought processes, and documents show the deficiency and potential ability. For example, one file suggests that most students didn't even think that injury can be a cause for abdominal pain. Thus, the teacher can obtain valuable information on what the students have missed or what they forgot to do or ask based on the recordings from each station.

CDIO is a satisfied approach to better reveal the various problems of learning and performance students encounter during rotations while hastening the learning and improvement in performance through a safe medical environment.

Although the type and clarity of instructions and level of complexity of program varied between different courses, the CDIO methodology received very satisfactory comments from all participants. Participants expressed that the CDIObased experience at Yangzhou University was better than the previously learning. The candidate was now able to show how 
he/she could integrate the information obtained from the clinical with the proper diagnostic blood and imagine studies from the course to develop a realistic differential diagnosis and plan.

Overall the CDIO concept or methodology has the following advantages:

1) CDIO -based program uses all qualified cases, all coming from real patients.

2) Educators can get the information from clinical and easily to make up a scenario to be used.

3) The faculty can get real time students performance and give them immediate feedback for proper learning and personalized teaching since the utility record provides deficient and incomplete information.

4) The students experience the process of making a real diagnosis.

Our study has some limitations by relatively small numbers of participants and a limited number of cases. We plan to design a study with more examinees and more cases so we can further compare the CDIO-based and PBL or CBL-based program advantages and disadvantages.

\section{Conclusion}

Using the CDIO methodology to design teaching and learning is an effective method as shown by the results in this study and by the feedback obtained from students. CDIO could be useful in medical education. However, further design and experimentation must be done before such methodology can be considered for an extensive use.

\section{References}

[1] Van der Vleuten CPM, Norman GR, De Graaff E, "Pitfalls in the pursuit of objectivity: issues of reliability," Med Educ, PP. 110-118, 1991.

[2] Downing SM, "Validity: on meaningful interpretation of assessment data," Med Educ, PP. 830-837, 2003.

[3] Okuda Y, Bryson EO, DeMaria S Jr, Jacobson L, Quinones J, Shen B, Levine AI, "The utility of simulation in medical education: what is the evidence?" Mt Sinai J Med, PP. 330-343, 2009.

[4] Gaba DM, "The future vision of simulation in health care," Qual Saf Health Care, PP. i2-i10, 2004.

[5] Baroffio, A., Nendaz, M. R., Perrier, A., \& Vu, N. V, "Tutor training, evaluation criteria and teaching environment influence students' ratings of tutor feedback in problem-based learning," Advance Health Science Education Theory Practice, pp. 427 439, 2007.

[6] Daniel Wiznia, Robert Korom, Peter Marzuk, Joseph Safdieh, Bernice Grafstein, "PBL 2.0: enhancing problem-based learning through increased student participation," Med Educ Online, pp. 3402, 2012.

[7] Francine D. Salinitri, Mary Beth O'Connell, Candice L. Garwood, Victoria Tutag Lehr, Karina Abdallah, "An Objective Structured Clinical Examination to Assess ProblemBased Learning," Am J Pharm Educ, pp. 44, 2012. 